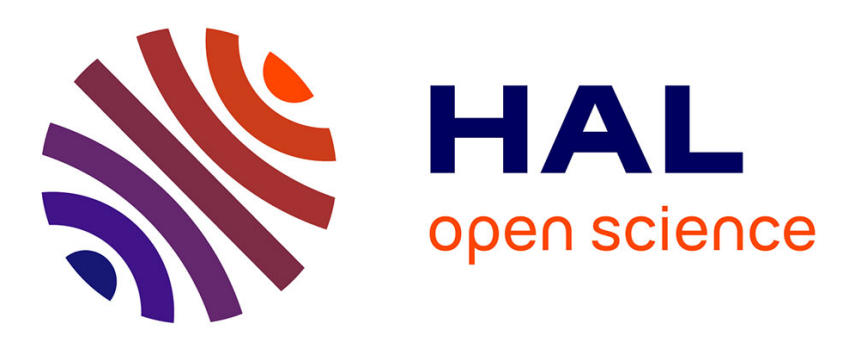

\title{
Natalizumab in secondary progressive multiple sclerosis
}

Gilles Edan

\section{To cite this version:}

Gilles Edan. Natalizumab in secondary progressive multiple sclerosis. The Lancet Neurology, 2018, 17 (5), pp.384-385. 10.1016/S1474-4422(18)30108-X . inserm-02457667

\section{HAL Id: inserm-02457667 https://www.hal.inserm.fr/inserm-02457667}

Submitted on 28 Jan 2020

HAL is a multi-disciplinary open access archive for the deposit and dissemination of scientific research documents, whether they are published or not. The documents may come from teaching and research institutions in France or abroad, or from public or private research centers.
L'archive ouverte pluridisciplinaire HAL, est destinée au dépôt et à la diffusion de documents scientifiques de niveau recherche, publiés ou non, émanant des établissements d'enseignement et de recherche français ou étrangers, des laboratoires publics ou privés. 


\section{(1) Natalizumab in secondary progressive multiple sclerosis}

Published Online March 12, 2018 http://dx.doi.org/10.1016/ S1474-4422(18)30108-X See Articles page 405
Although several disease-modifying treatments are available for relapsing types of multiple sclerosis, additional treatment options for progressive types of multiple sclerosis are needed, especially since the available treatments tend to focus on patients who are actively relapsing. In this context, the ASCEND trial by Raju Kapoor and colleagues ${ }^{1}$ was a two-part study that assessed whether natalizumab slows disease progression unrelated to relapse in patients with secondary progressive multiple sclerosis. Part 1 was a randomised, placebo-controlled, double-blind study, comprising 888 patients with secondary progressive multiple sclerosis (439 in the natalizumab group and 449 in the placebo group) who were followed up for 2 years. Part 2 was an optional 2-year, open-label, extension study, comprising 565 participants (291 continuing natalizumab and 274 initiating natalizumab). Part 2 was terminated by the funder of the study after the results of part 1 emerged, before completion of year 4 of the study, thus limiting available data to 156 weeks of follow-up.

The ASCEND trial did not meet the multicomponent primary endpoint for part 1 assessed at 2 years. No treatment effect was observed on two components of the primary endpoint that measure progression of ambulatory disability: the Expanded Disability Status Scale (EDSS) and the Timed 25-Foot Walk (T25FW). However, natalizumab treatment was associated with a nominally significant $44 \%$ reduction in the relative risk of confirmed upper-limb disability progression as measured by the 9-Hole Peg Test (9HPT), the third component of the primary endpoint (15\% with natalizumab vs $23 \%$ with placebo; adjusted odds ratio 0.56 [95\% Cl 0.40-0.80]; $\mathrm{p}=0.001)$.

The results of this phase 3 trial are in line with those of the IMPACT trial, ${ }^{2}$ which investigated interferon beta $1 \mathrm{a}$ in secondary progressive multiple sclerosis, in patients with similar baseline demographics (age and disease duration) to those enrolled in the ASCEND trial. $A$ reduction in the relative risk of confirmed upperlimb disability progression, as measured by the 9HPT, but no clinical effect on ambulatory disability, were documented in both IMPACT ${ }^{2}$ and ASCEND. ${ }^{1}$

The observed discrepancies between lower-limb and upper-limb disability need addressing. The authors of the ASCEND trial ${ }^{1}$ pointed out that residual degeneration should abate more quickly in shorter axon pathways than in longer ones because shorter axons have a lower lesion burden. However, another potential explanation not offered by the authors might be that the progressive phase presents as gradual, insidious ambulatory worsening (ie, lower-limb disability expression [EDSS 3.5-6.5]). Conversely, in the ASCEND trial, there was no clear evidence of a gradual, insidious, progressive course unrelated to disease activity for upper-limb disability worsening. This consideration lends itself to two possibilities: natalizumab treatment had a positive clinical effect on upper limbs either through its effects on disease activity (which is strongly supported by its well documented effect on both annual relapse rate and MRI activity) or through its effects on the insidious neurodegenerative process, independently of focal inflammatory disease activity.

To address this important question, the effect of natalizumab versus placebo on upper-limb disability performance could be assessed in patients younger than 50 years versus those older than 50 years and according to the duration of the progressive phase after the onset of progression (duration $<5$ years vs $>5$ years), since disease activity is substantially dependent on age and time since onset. ${ }^{3}$ If natalizumab has a similar positive effect on upper-limb performance regardless of the age of the patients or the duration of the progressive phase, this result will be a clear demonstration that natalizumab has a real effect on the neurodegenerative process independently of the focal inflammatory process (the fundamental feature of multiple sclerosis progression). If, however, the reduction of upper-limb worsening is restricted to patients with secondary progressive multiple sclerosis who are younger than 50 years and who have a duration of the progressive phase shorter than 5 years, as observed with the interferon beta ${ }^{4,5}$ and anti-CD20 $0^{6,7}$ phase 3 clinical trials, one could conclude that natalizumab affects disability worsening in secondary progressive multiple sclerosis by influencing disease activity, which is still present in the early phase of secondary progressive multiple sclerosis.

The debate around initiation of natalizumab treatment in patients with secondary progressive multiple sclerosis with worsening disability unrelated to relapse remains unresolved. Taking into account the 
benefits, risks, and costs of natalizumab treatment, it might be reasonable to first consider on an annual basis the phenotype descriptors, as defined by Lublin and colleagues, ${ }^{8}$ including references to disease activity (based on clinical relapse rate and imaging findings) and disease progression. One might propose the use of natalizumab in secondary progressive multiple sclerosis only in those patients who have both active disease and worsening disease.

\section{Gilles Edan}

CIC1414 INSERM, CHU Pontchaillou, Rennes 35033, France gilles.edan@chu-rennes.fr

I have received consultancy fees and non-personal research grants from Merck, Novartis, Biogen, and Sanofi, and grants from Teva, outside the area of work being commented on here.
Kapoor R, Ho P-R, Campbell N, et al. Effect of natalizumab on disease progression in secondary progressive multiple sclerosis (ASCEND): a phase 3, randomised, double-blind, placebo-controlled trial with an open-label extension. Lancet Neurol 2018; published online March 12. http://dx.doi.org/10.1016/S1474-4422(18)30069-3.

2 Cohen JA, Cutter GR, Fischer JS, et al. Benefit of interferon beta-1a on MSFC progression in secondary progressive MS. Neurology 2002; 59: 679-87.

3 Tremlett H, Zhao Y, Joseph J, Devonshire V, the UBCMS Clinic Neurologists. Relapses in multiple sclerosis are age- and time-dependent J Neurol Neurosurg Psychiatry 2008; 79: 1368-74.

4 European Study Group on interferon beta-1b in SPMS. Placebo-controlled multicentre randomised trial of interferon beta- $1 \mathrm{~b}$ in treatment of secondary progressive multiple sclerosis. Lancet 1998; 352: 1491-97.

5 Panitch $\mathrm{H}$, Miller A, Paty D, et al. Interferon beta- 1 b in secondary progressive MS: results from a 3-year controlled study. Neurology 2004 63: 1788-95.

6 Hawker $\mathrm{K}, \mathrm{O}^{\prime}$ Connor P, Freedman MS, et al. Rituximab in patients with primary progressive MS. Results of a randomized double blind placebo controlled trial. Ann Neurol 2009; 66: 960-71.

7 Montalban X, Hauser SL, Kappos L, et al. Ocrelizumab versus placebo in primary progressive multiple sclerosis. N EnglJ Med 2017; 376: 209-20

8 Lublin F, Reingold ST, Cohen JA, et al. Defining the clinical course of multiple sclerosis. The 2013 revisions. Neurology 2014; 83: 278-86.

\section{Riluzole, disease stage and survival in ALS}

Following pivotal clinical trials in amyotrophic lateral sclerosis (ALS), approval of riluzole by the US Food and Drug Administration in 1995 was met with optimism. Despite being associated with a short survival benefit of 2-3 months equating to a $9 \%$ increase in 1 -year survival, ${ }^{1,2}$ the subsequent adoption of riluzole as a treatment for ALS was perhaps reflective of a desperate need for therapeutic options in the face of this devastatingly progressive disease. ${ }^{3}$ More than two decades after riluzole was first approved for ALS, a more efficacious treatment is yet to be discovered.

Despite increasing scientific rhetoric on the subject, the mechanism of therapeutic benefit afforded by riluzole remains undetermined. Several pathways have been postulated, ranging from central anti-glutaminergic modulation of excitotoxic pathways, mitochondrial function, and changes to fat metabolism, to peripheral axonal effects on persistent sodium channel function and potentiation of calcium-dependent potassium currents. ${ }^{4}$ To clarify the mechanism of action of riluzole in patients with ALS, a post-hoc study by Ton Fang and colleagues published in The Lancet Neurology ${ }^{5}$ selectively explored the potential for riluzole to exert differential effects across disease stages. Analysing data from the original doseranging trial comprising 959 patients randomly assigned to riluzole (50 mg/day, $100 \mathrm{mg} /$ day, or $200 \mathrm{mg} /$ day) or placebo, ${ }^{6}$ Fang and colleagues showed that $100 \mathrm{mg} /$ day of riluzole was associated with longer survival in the last clinical stage of ALS before death (stage 4) compared with placebo (hazard ratio $0.55,95 \% \mathrm{Cl} 0.36-0.83$; log rank $p=0.037$ ). The time from stages 2 or 3 to subsequent stages or death did not differ between riluzole treatment groups and placebo. These findings suggest that the disease-modulatory effects and survival benefits of riluzole occur in an advanced stage of disease.

Although the earliest stage of ALS was not analysed in the current study by Fang and colleagues, findings from several open-label non-randomised trials have suggested that the greatest benefit occurs at earlier disease stages..$^{7-9}$ Early disease modulation was also suggested by findings from another study, ${ }_{1}^{10}$ which showed that partial normalisation of central and peripheral dysfunction occurred in the first 8 weeks of riluzole use in patients with relatively early-stage ALS. The argument for earlier efficacy might seem more conceptually feasible than later effects, given the lower likelihood that any treatment could confer a significant neuroprotective effect within a severely depleted population of dead and dying motor neurons, such as might occur in the advanced disease stages of ALS. The contrasting notion proposed by Fang and colleagues, suggesting benefit at the endpoint of the disease, warrants careful reconsideration of these hypotheses. Specifically, perhaps riluzole might affect or activate different therapeutic pathways dependent on disease stage. For example, modulation of excitotoxicity oa Published Online March 7, 2018 http://dx.doi.org/10.1016/ S1474-4422(18)30091-7 See Articles page 416 